\title{
Interstitial cystitis - intravesical treatment
}

\author{
Participants: \\ Fernando Gonçalves de Almeida \\ (iD) Nelson Sivonei da Silva Batezini ${ }^{1}$ \\ (iD) Ricardo Santos Simões ${ }^{2}$ \\ (iD) Wanderley M Bernardo²
}

Contact: carloshenriquesb@yahoo.com.br

Final version: January 5th, 2018

1. Brazilian Society of Urology, Rua Real Grandeza, 108 sala 101 - Botafogo, Rio de Janeiro - RJ, Brasil 2. Brazilian Medical Association, Rua São Carlos do Pinhal, 324 - Bela Vista, São Paulo - SP, Brasil

http://dx.doi.org/10.1590/1806-9282.65.4.535

The Guidelines Project, an initiative of the Brazilian Medical Association, aims to combine information from the medical field in order to standardize producers to assist the reasoning and decision-making of doctors.

The information provided through this project must be assessed and criticized by the physician responsible for the conduct that will be adopted, depending on the conditions and the clinical status of each patient.

\section{INTRODUCTION}

Interstitial cystitis (IC), also known as Bladder Pain Syndrome (BPS) is a chronic disease of unknown etiology and progressive in nature characterized by the presence of pain and accompanied by irritating urinary symptoms in the absence of other identifiable causes. ${ }^{1}$. Since it was first described by Skene in 1887 , who characterized it is an inflammatory process that involves the entire or part of the bladder mucosa and can reach the muscle wall, studies on its etiology and physiopathology have not been successful in elucidating its specific mechanism. Thus, the therapeutic approach is a complex subject that includes behavioral, pharmacological and even surgical interventions with the main objective of restoring the bladder function, preventing recurrence and improving the quality of life ${ }^{2}$.

Among the pharmacological arsenal available is the intravesical treatment, in which the drugs are applied directly to the inner surface of the bladder mucosa; the main representatives of this strategy are the dimethyl sulfoxide (DMSO), hyaluronic acid (HA), resiniferatoxin, pentosan polysulfate sodium (PPS), lidocaine, chondroitin sulfate (CS), botulinum toxin type A (BoNTA), and Bacillus Calmette-Guérin (BCG). Intravesical instillation has the advantage of providing high concentrations of the drug directly to the vesical urothelium, with the rationale of recovery of the glycosaminoglycans layer, acting on the process of inflammation and hypersensitivity. In addition, it minimizes systemic effects.

\section{METHODOLOGY}

The purpose of this guideline is to present the doctors, specialists and healthcare establishments with the main intravesical drug therapies employed for managing interstitial cystitis. In relation to the outcome, complaints of pain, frequency, urgency and bladder capacity were assessed. A systematic review of the literature was performed, without period restriction, in the Medline database, retrieving 112 papers, of which 15 were selected to respond to the clinical question: What are the primary intravesical drug therapies used in Brasil to manage interstitial cystitis? The search strategy used was: (interstitial cystitis, or Cystitides, Interstitial or INTERSTITIAL 
Cystitides OR interstitial cystitis OR Painful Bladder Syndrome OR Chronic interstitial cystitis, OR Chronic Interstitial Cystitides or Cystitides, Chronic interstitial or INTERSTITIAL Cystitides, Chronic OR interstitial cystitis, Chronic OR Chronic interstitial cystitis) AND (Therapy/3,437[filter]). The selection of the studies and the evaluation of the titles and abstracts obtained from the search strategy in the databases consulted were independently and blindly conducted, in total accordance with the inclusion and exclusion criteria. Finally, studies with potential relevance were separated. When the title and the summary were not enlightening, we sought for the full article. Only studies with texts available in its entirety were considered for critical evaluation. We included studies available in Portuguese, English, Spanish, French, or Italian. Through this search, we were able to obtain evidence that the treatment with DMSO, HA, PPS and botulinum toxin type A seem to be associated with the improvement of symptoms experienced by individuals with IC/BPS. The details of the methodology and the results of this guideline are set out in Annex I.

\section{RESULTS}

The results regarding the treatment of patients with interstitial cystitis using dimethyl sulfoxide, hyaluronic acid, resiniferatoxin, pentosan polysulfate sodium, lidocaine, chondroitin sulfate, botulinum toxin type A, and Bacillus Calmette-Guérin will be presented.

For individuals in which therapeutic failure was observed even after the introduction of non-pharmacological behavioral measures or of the oral-systemic treatment, the inclusion of agents locally instilled in the bladder mucosa is the next therapeutic resource. An important point to be considered is that the introduction of pharmacological strategies must be conducted in parallel to the maintenance of behavioral changes that include changes in lifestyle such as diet, exercise, and bladder training, in addition to pain control.

\section{Dimethyl sulfoxide}

DMSO is an organic chemical compound whose mechanism of action has not been fully established. Several pharmacological properties have been identified as a result of its ability to interact with nucleic acids, carbohydrates, lipids, and proteins. It has also been reported that DMSO may act in the release of nitric oxide from afferent neurons, a mechanism that could possibly be related to the desensitization of nociceptive pathways of the urinary tract. Thus, it could act in the inflammatory process, relaxing the detrusor and inhibiting the degranulation of mast cells $^{3}(B)^{4}(D)$.

A clinical trial conducted by Perez-Marrero et al. randomized patients $(\mathrm{n}=33)$ with the diagnosis of interstitial cystitis to treatment with DMSO (50 $\mathrm{mL}$ of DMSO at $50 \%$ ) or placebo (B). Subsequently, instillations were conducted every fortnight until a total number of four sessions was reached; then the results were analyzed ${ }^{5}(\mathrm{~B})$. This study found a significant improvement of individuals treated with DMSO regarding complaints of pain and urgency, with improvement in bladder capacity; this was assessed both objectively (93\% versus $35 \%$, respectively) and subjectively (53\% versus $18 \%$, respectively) 5 (B). In corroboration to these findings, another clinical trial conducted by Peeker et al. found that patients with classical interstitial cystitis, when randomized for treatment with DMSO, compared to those who received BCG, had improved levels of complaint of pain and urinary frequency ${ }^{6}(B)$.

\section{Hyaluronic Acid (HA)}

AH is a non-sulfated glycosaminoglycan (GAG) of high molecular weight composed of repeated disaccharide units of D-glucuronic acid and H-acetylglucosamine. It is the most abundant GAG found on the extracellular matrix, and due to its molecular characteristics, it can influence the process of cell proliferation, differentiation, and repair of tissues. In recent years, the reconstruction of the GAG layer has gained emphasis in the treatment of IC/BPS, since this layer could act as a protective barrier of the urothelium, with several series published on the topic ${ }^{7}(D)^{8-11}(C)$.

Riedl et al. prospectively studied the effectiveness of the HA in patients with a diagnosis of interstitial cystitis as first-line therapy ${ }^{12}(\mathrm{~B})$. The weekly instillations of HA were administered until the patients showed significant improvement or complete interruption of symptoms. In this study, the assessment was based on a non-standardized questionnaire attributing scores for symptoms through a Visual Ana$\log$ Scale (VAS). The impact on quality of life and willingness to undergo a repetition of instillation were also checked.

Eighty-five percent of the patients reported im- 
provement of symptoms, $84 \%$ reported improvement in the quality of life, and $86 \%$ would repeat the treatment if necessary ${ }^{12}(B)$. Thirty-four percent had a recurrence of symptoms and demanded additional in-

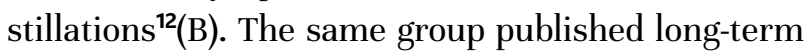
follow-up data of 48 patients of this cohort who were contacted in an average follow-up of five years ${ }^{13}(\mathrm{~B})$. Fifty percent (24/48) showed sustained improvement and did not require additional treatment ${ }^{13}(\mathrm{~B})$.

Similarly, a prospective study that randomized patients $(n=60)$ with a diagnosis of interstitial cystitis to different treatment regimens with hyaluronic acid (weekly instillations of $40 \mathrm{mg}$ of $\mathrm{AH}$ for four weeks and then monthly for 5 months or 12 instillations of $40 \mathrm{mg}$ of AH every two weeks), found that in both groups, the patients showed an improvement in the total score of ICSI (O'Leary-Sant Interstitial Cystitis Symptom Index $)^{14}(\mathrm{~B})$.

\section{Resiniferatoxin}

Resiniferatoxin is a potent analog of capsaicin, an alkaloid derived from pepper that promotes the temporary depletion of substance $\mathrm{P}$, which is a neuropeptide regarded as one of the main responsible for the transmission of pain impulses through peripheral sensory nerve fibers of type C. This action could inhibit the transmission of impulses to the central nervous system, which in theory could alleviate the symptoms related to IC/BPS.

Although the clinical efficacy of resiniferatoxin has been demonstrated in small studies, these results were not confirmed in controlled studies with a placebo ${ }^{15-17}(\mathrm{C})$. A randomized clinical trial designed to analyze the performance of a single intravesical dose of $50 \mathrm{~mL}$ resiniferatoxin at different concentrations $(0.01 ; 0.05$, and $0.10 \mu \mathrm{g})$ did not find, at the end of the 12th week of follow-up, an improvement in pain, urgency, frequency, or nocturia ${ }^{18}(\mathrm{~B})$.

\section{Pentosan polysulfate sodium (PPS)}

The mechanism of action of PPS is not fully understood, but it is believed that it helps in repairing the glycosaminoglycan layer that coats the vesical urothelium, reducing the permeability to potassium ions, toxins, and bacteria to the bladder wall, therefore preventing the activation of mast cells and inflammatory reaction and the consequent symptomatology ${ }^{19}(\mathrm{C})$. Blade et al., in a randomized clinical trial, found that patients with a diagnosis of interstitial cystitis treated with intravesical PPS (300 mg in $50 \mathrm{~mL}$ of $0.9 \% \mathrm{SS}$ twice a week for three months), presented a significant relief in symptoms compared to those who received a placebo ${ }^{20}(\mathrm{~B})$. Confirming these findings, another clinical trial, which randomized women with interstitial cystitis to combined treatment of oral and intravesical PPS or oral PPS and intravesical placebo, found, at the end of the 12-week follow-up, a reduction of $46 \%$ in ICSI scores (O'LearySant Interstitial Cystitis Symptom Index) for the first group over compared to $24 \%$ observed for those who received the placebo ${ }^{21}(\mathrm{~B})$. The health-related quality of life domains also showed a significant improvement in the group treated with intravesical PPS $^{21}(B)$.

\section{Lidocaine}

Lidocaine is a topical anesthetic that when applied in the vesical urothelium is believed to prevent the transmission of painful impulses originated in the lower urinary tract associated with the symptoms of interstitial cystitis. One of the major studies that analyzed the performance of this drug was published in 2009 by Nickle et al. ${ }^{22}(B)$. In this multicenter study, 102 patients were randomized to treatment with $10 \mathrm{~mL}$ of $200 \mathrm{mg}$ alkalized lidocaine or placebo for five consecutive days ${ }^{22}(\mathrm{~B})$. After 29 days of instillation, they found that $30 \%$ of patients treated with lidocaine showed improvement in symptoms in comparison to only $9.6 \%$ of those who received the placebo $^{22}(\mathrm{~B})$. However, after ten days, the symptoms returned to the levels identified at the beginning of the study ${ }^{22}(\mathrm{~B})$.

\section{Chondroitin sulfate (CS)}

Chondroitin sulfate (CS) is a sulfated GAG present in the extracellular matrix of connective tissues. Theoretically, the instillation of this GAG could promote the recovery of the protective barrier of the urothelium. Thus, with the objective of analyzing the effectiveness of the instillation of chondroitin sulfate in the bladder of interstitial cystitis patients, Nickle et al., designed a multicenter clinical trial in which patients were randomized for treatment with CS (weekly Instillations for six weeks) or a placebo, and the outcomes were analyzed in the 12th week of follow-up ${ }^{23}(\mathrm{~B})$. At the end of follow-up, they did not find any difference between the groups in the evaluation 
using the Global Response Assessment (GRA) questionnaire ${ }^{23}(B)$. Similar results were found in a subsequent publication by the same author ${ }^{24}(\mathrm{~B})$.

\section{Botulinum toxin type $\mathrm{A}$ (BoNTA)}

Botulinum Toxin is an exotoxin produced by Clostridium Botulinum, a sporulating gram-positive anaerobic organism. It is to be noted that different serotypes produce different toxins. Botulinum toxin has a great influence on nerve cells, establishing a link with the neuronal membrane of the nerve terminal, at the level of the neuromuscular junction. Botulinum toxin type A acts on the peripheral cholinergic nerve terminal by inhibiting the release of acetylcholine, through the action of metalloendoproteinases. In addition, it is able to inhibit the release of pre- and post-ganglionic neurotransmitters of the cholinergic nerve terminal of the autonomous nervous system. Therefore, it entails a reversible but transient chemical denervation on the functioning of the motor plate. Thus, this toxin causes inactivity of the muscle, which in the specific case of the detrusor muscle, could benefit individuals with interstitial cystitis ${ }^{25}(\mathrm{C})$.

Despite numerous published studies showing that intravesical injections of botulinum toxin A (100 to 200 units) result in high response rates, the evidence currently available on the use of the BoNTA is inconclusive ${ }^{26-28}(\mathrm{C})^{29.30}(\mathrm{~B})$.

A clinical trial conducted by Manning et al. in 2014 randomized 54 women with resistant severe interstitial cystitis to treatment with hydrodistention and intravesical instillation of BoNTA or hydrodistention and intravesical instillation of saline solution $^{31}(\mathrm{~B})$. At the end of the three-month follow-up, they did not observe significant differences between the groups from the analysis conducted using the O'Leary-Sant questionnaire ${ }^{31}(\mathrm{~B})$. On the other hand, a multicenter clinical trial found, at the 8th week of follow-up, that individuals randomized to treatment with hydrodistention and BoNTA (100U) showed significant reduction in pain in comparison with patients undergoing intravesical instil- lation of saline solution $(-2.6 \pm 2.8$ versus $-0.9 \pm 2.2$, respectively, with $\mathrm{p}=0.021)^{32}(\mathrm{~B})$.

\section{Bacillus calmette-guérin (BCG)}

The mechanism of action of BCG is not yet fully understood. In theory, it is believed to cause negative regulation of interleukin-6, a response that is increased in individuals with interstitial cystitis. For this reason, there is an interest in conducting studies that investigate the performance of intravesical instillation of BCG in patients with a diagnosis of IC/ $\mathrm{BPS}^{33-36}(\mathrm{~B})$. A clinical trial designed by Irani et al. examined the effectiveness of the intravesical instillation of BCG in a dose of $120 \mathrm{mg}$ applied weekly for six weeks ${ }^{34}(\mathrm{~B})$. With an average follow-up of 24 months (six to 33 months), they found a significant improvement in the complaints associated with interstitial cystitis in patients who had been randomized for treatment with BCG in comparison with the placebo group (73\% versus $20 \%$, respectively) ${ }^{34}(\mathrm{~B})$. On the other hand, another study that included a larger number of patients (over 260 individuals) did not find, at the end of the 34-week follow-up, any difference in the evaluation conducted using the Global Response Assessment questionnaire among individuals submitted or not to the instillation of BCG (21\% versus $12 \%$, respectively, with $\mathrm{p}=0.062)^{36}(\mathrm{~B})$.

\section{RECOMMENDATION}

The treatment of IC/BPS represents a challenge in clinical practice since it is a multifactorial chronic disease of unknown etiology. Despite the wide use of intravesical agents, more controlled studies are necessary for establishing their real effectiveness.

Based on the evidence currently available, DMSO, HA, PPS and botulinum toxin type A seem to be associated with the improvement in symptoms experienced by individuals with IC/BPS; however, such results should be taken with caution given the restricted number of randomized clinical trials that study these treatments (37). 


\section{REFERENCES}

1. Patnaik SS, Laganà AS, Vitale SG, Butticè S, Noventa M, Gizzo S, Valenti G, Rapisarda AMC, La Rosa VL, Magno C, Triolo O, Dandolu V. Etiology, pathophysiology and biomarkers of interstitial cystitis/painful bladder syndrome. Arch Gynecol Obstet. 2017;295(6):1341-1359. Review. PubMed PMID: 28391486.

2. Rovner E, Propert KJ, Brensinger C, Wein AJ, Foy M, Kirkemo A, Landis JR, Kusek JW, Nyberg LM. Treatments used in women with interstitial cystitis: the interstitial cystitis database (ICDB) study experience. The Interstitial Cystitis Data Base Study Group. Urology. 2000;56(6):940-5. PubMed PMID: 11113737.

3. Sun Y, Chai TC. Effects of dimethyl sulphoxide and heparin on stretch-activated ATP release by bladder urothelial cells from patients with interstitial cystitis. BJU Int. 2002;90(4):381-5. PubMed PMID: 12175393.

4. Nazif O, Teichman JM, Gebhart GF. Neural upregulation in interstitial cystitis. Urology. 2007;69(4 Suppl):24-33. Review. PubMed PMID: 17462476.

5. Perez-Marrero R, Emerson LE, Feltis JT. A controlled study of dimethyl sulfoxide in interstitial cystitis. | Urol. 1988;140(1):36-9. PubMed PMID: 3288775.

6. Peeker R, Haghsheno MA, Holmäng $S$, Fall $M$. Intravesical bacillus Calmette-Guerin and dimethyl sulfoxide for treatment of classic and nonulcer interstitial cystitis: a prospective, randomized double-blind study. | Urol. 2000;164(6):1912-5; discussion 1915-6. PubMed PMID: 11061879 .

7. Madersbacher H, van Ophoven A, van Kerrebroeck PE. GAG layer replenishment therapy for chronic forms of cystitis with intravesical glycosaminoglycans-a review. Neurourol Urodyn. 2013;32(1):9-18. Review. PubMed PMID: 22782909.

8. Porru D, Campus G, Tudino D, Valdes E, Vespa A, Scarpa RM, Usai E. Results of treatment of refractory interstitial cystitis with intravesical hyaluronic acid. Urol Int. 1997;59(1):26-9. PubMed PMID: 9313320.

9. Daha LK, Riedl $C R$, Lazar $D$, Hohlbrugger $G$, Pflüger $H$. Do cystometric findings predict the results of intravesical hyaluronic acid in women with interstitial cystitis? Eur Urol. 2005;47(3):393-7; discussion 397. PubMed PMID: 15716206.

10. Kallestrup EB, Jorgensen SS, Nordling J, Hald T. Treatment of interstitial cystitis with Cystistat: a hyaluronic acid product. Scand J Urol Nephrol. 2005;39(2):143-7. PubMed PMID: 16032779.

11. Morales A, Emerson L, Nickel JC. Intravesical hyaluronic acid in the treatment of refractory interstitial cystitis. Urology. 1997;49(5A Suppl):111-3. PubMed PMID: 9146012

12. Riedl $C R$, Engelhardt PF, Daha KL, Morakis N, Pflüger H. Hyaluronan treatment of interstitial cystitis/painful bladder syndrome. Int Urogynecol J Pelvic Floor Dysfunct. 2008;19(5):717-21. PubMed PMID: 18097627.

13. Engelhardt PF, Morakis N, Daha LK, Esterbauer B, Riedl CR. Long-term results of intravesical hyaluronan therapy in bladder pain syndrome/ interstitial cystitis. Int Urogynecol J. 2011;22(4):401-5. PubMed PMID: 20938644.

14. Lai MC, Kuo YC, Kuo HC. Intravesical hyaluronic acid for interstitial cystitis/painful bladder syndrome: a comparative randomized assessment of different regimens. Int | Urol. 2013;20(2):203-7. PubMed PMID: 22925498.

15. Apostolidis A, Gonzales GE, Fowler C). Effect of intravesical Resiniferatoxin (RTX) on lower urinary tract symptoms, urodynamic parameters, and quality of life of patients with urodynamic increased bladder sensation. Eur Urol. 2006;50(6):1299-305. PubMed PMID: 16697519.

16. Peng $\mathrm{CH}$, Kuo HC. Multiple intravesical instillations of low-dose resiniferatoxin in the treatment of refractory interstitial cystitis. Urol Int. 2007;78(1):78-81. PubMed PMID: 17192738.

17. Lazzeri M, Spinelli M, Beneforti P, Malaguti S, Giardiello G, Turini D. Intravesical infusion of resiniferatoxin by a temporary in situ drug delivery system to treat interstitial cystitis: a pilot study. Eur Urol. 2004;45(1):98102. PubMed PMID: 14667524.

18. Payne CK, Mosbaugh PG, Forrest IB, Evans RJ, Whitmore KE, Antoci IP, Perez-Marrero R, Jacoby K, Diokno AC, O'Reilly KJ, Griebling TL, Vasavada SP, Yu AS, Frumkin LR; ICOS RTX Study Group (Resiniferatoxin Treatment for Interstitial Cystitis). Intravesical resiniferatoxin for the treatment of interstitial cystitis: a randomized, double-blind, placebo controlled trial. | Urol. 2005;173(5):1590-4. PubMed PMID: 15821499.

19. Chiang G, Patra P, Letourneau R, Jeudy S, Boucher W, Green M, Sant GR, Theoharides TC. Pentosanpolysulfate inhibits mast cell histamine secretion and intracellular calcium ion levels: an alternative explanation of its beneficial effect in interstitial cystitis. J Urol. 2000;164(6):2119-25. PubMed PMID: 11061939.

20. Bade JJ, Laseur M, Nieuwenburg A, van der Weele LT, Mensink HJ. A placebo-controlled study of intravesical pentosanpolysulphate for the treatment of interstitial cystitis. Br J Urol. 1997;79(2):168-71. PubMed PMID: 9052464.

21. Davis EL, El Khoudary SR, Talbott EO, Davis J, Regan LI. Safety and efficacy of the use of intravesical and oral pentosan polysulfate sodium for interstitial cystitis: a randomized double-blind clinical trial. J Urol. 2008:179(1):177-85. PubMed PMID: 18001798.

22. Nickel JC, Moldwin R, Lee S, Davis EL, Henry RA, Wyllie MG. Intravesical alkalinized lidocaine (PSD597) offers sustained relief from symptoms of interstitial cystitis and painful bladder syndrome. BJU Int. 2009;103(7):9108. PubMed PMID: 19021619

23. Nickel JC, Egerdie RB, Steinhoff G, Palmer B, Hanno P. A multicenter, randomized, double-blind, parallel group pilot evaluation of the efficacy and safety of intravesical sodium chondroitin sulfate versus vehicle control in patients with interstitial cystitis/painful bladder syndrome. Urology. 2010;76(4):804-9. PubMed PMID: 20494413.

24. Nickel JC, Hanno P, Kumar K, Thomas H. Second multicenter, randomized, double-blind, parallel-group evaluation of effectiveness and safety of intravesical sodium chondroitin sulfate compared with inactive vehicle control in subjects with interstitial cystitis/bladder pain syndrome. Urology. 2012;79(6):1220-4. PubMed PMID: 22516357.

25. Ikeda Y, Zabbarova IV, Birder LA, de Groat WC, McCarthy C), Hanna-Mitchell AT, Kanai AJ. Botulinum neurotoxin serotype $A$ suppresses neurotransmitter release from afferent as well as efferent nerves in the urinary bladder. Eur Urol. 2012;62(6):1157-64. PubMed PMID: 22480459.

26. Pinto R, Lopes T, Frias B, Silva A, Silva A, Silva CM, Cruz C, Cruz F, Dinis P. Trigonal injection of botulinum toxin $A$ in patients with refractory bladder pain syndrome/interstitial cystitis. Eur Urol. 2010;58(3):360-5. PubMed PMID: 20227820

27. Giannantoni A, Cagini R, Del Zingaro M, Proietti S, Quartesan R, Porena $M$, Piselli M. Botulinum A toxin intravesical injections for painful bladder syndrome: impact upon pain, psychological functioning and Quality of Life. Curr Drug Deliv. 2010;7(5):442-6. PubMed PMID: 20950262.

28. Giannantoni A, Porena M, Costantini E, Zucchi A, Mearini L, Mearini E. Botulinum A toxin intravesical injection in patients with painful bladder syndrome: 1-year followup. J Urol. 2008;179(3):1031-4. PubMed PMID: 18206941.

29. Gao Y, Liao L. Intravesical injection of botulinum toxin A for treatment of interstitial cystitis/bladder pain syndrome: 10 years of experience at a single center in China. Int Urogynecol J. 2015;26(7):1021-6. PubMed PMID: 25690160.

30. Lee CL, Kuo HC. Long-Term Efficacy and Safety of Repeated Intravescial OnabotulinumtoxinA Injections Plus Hydrodistention in the Treatment of Interstitial Cystitis/Bladder Pain Syndrome. Toxins (Basel). 2015;7(10):4283-93. PubMed PMID: 26506388.

31. Manning J, Dwyer P, Rosamilia A, Colyvas K, Murray C, Fitzgerald E. A multicentre, prospective, randomised, double-blind study to measure the treatment effectiveness of abobotulinum A (AboBTXA) among women with refractory interstitial cystitis/bladder pain syndrome. Int Urogynecol J. 2014;25(5):593-9. PubMed PMID: 24276074.

32. Kuo HC, Jiang YH, Tsai YC, Kuo YC. Intravesical botulinum toxin-A injections reduce bladder pain of interstitial cystitis/bladder pain syndrome refractory to conventional treatment - A prospective, multicenter, randomized, double-blind, placebo-controlled clinical trial. Neurourol Urodyn. 2016;35(5):609-14. PubMed PMID: 25914337.

33. Peters K, Diokno A, Steinert B, Yuhico M, Mitchell B, Krohta S, Gillette B, Gonzalez J. The efficacy of intravesical Tice strain bacillus Calmette-Guerin in the treatment of interstitial cystitis: a double-blind, prospective, placebo controlled trial. J Urol. 1997;157(6):2090-4. PubMed PMID: 9146587.

34. Irani $D$, Heidari M, Khezri AA. The efficacy and safety of intravesical Bacillus-Calmette-Guerin in the treatment of female patients with interstitial cystitis: a double-blinded prospective placebo controlled study. Urol J. 2004;1(2):90-3. PubMed PMID: 17874392.

35. Propert KJ, Mayer R, Nickel JC, Payne CK, Peters KM, Teal V, Burks D, Kusek JW, Nyberg LM, Foster HE; Interstitial Cystitis Clinical Trials Group. Followup of patients with interstitial cystitis responsive to treatment with 
intravesical bacillus Calmette-Guerin or placebo. I Urol. 2008:179(2):5525. PubMed PMID: 18082224

36. Mayer R, Propert KJ, Peters KM, Payne CK, Zhang Y, Burks D, Culkin DJ, Diokno A, Hanno P, Landis JR, Madigan R, Messing EM, Nickel JC, Sant GR, Warren I, Wein AJ, Kusek JW, Nyberg LM, Foster HE; Interstitial Cystitis Clinical Trials Group. A randomized controlled trial of intravesical bacillus calmette-guerin for treatment refractory interstitial cystitis. | Urol. 2005:173(4):1186-91. PubMed PMID: 15758738

37. Zhang W, Deng X, Liu C, Wang X. Intravesical treatment for interstitial cystitis/painful bladder syndrome: a network meta-analysis. Int Urogynecol J. 2017;28(4):515-525. Review. PubMed PMID: 27614759.
38. Levels of Evidence and Grades of Recommendations - Oxford Centre for Evidence Based Medicine. Disponível em URL: http://cebm.jr2.ox.ac.uk/ docs/ old_levels. Htm

39. Jadad AR, Moore RA, Carroll D, Jenkinson C, Reynolds DJ, Gavaghan DJ, et al. Assessing the quality of reports of randomized clinical trials: is blinding necessary? Control Clin Trials 1996; 17:1-12.

40. Wells G, Shea B, O'Connell D, Robertson J, Peterson J, Welch V, et al. The Newcastle-Ottawa Scale (NOS) for assessing the quality of nonrandomised studies in meta-analyses. Disponível em: http://www.ohri.ca/ programs/clinical_epidemiology/oxford.asp

41. Goldet G, Howick J. Understanding GRADE: an introduction. J Evid Based Med 2013; 6:50-4. 